\title{
The idea of constructing a Service-oriented Government Performance Audit Based on Balanced Score Card
}

\author{
Ming-Yue Liu* \\ School of Public Management \\ Yunnan University of Finance and Economics \\ Kunming, China \\ 383748595@qq.com
}

\author{
Qing-Hua Chen \\ Accounting School \\ Yunnan University of Finance and Economics \\ Kunming, China \\ 270271083@qq.com
}

\begin{abstract}
The performance evaluation is a key link in the process of building a service-oriented government, the most important purpose is to realize the government service performance optimization. Government performance audit is the main tool; the government performance evaluation should conform to the performance evaluation index system of serviceoriented government. Based on China's service-oriented government construction as the research background, based on the perspective of public management theory, follow the principle of civil standard of public services, with the aid of the balanced scorecard method, from the dimension of evaluation, the weight of the selection of evaluation index, evaluation set three aspects to build a service-oriented government performance audit evaluation system.
\end{abstract}

Keywords-Service-oriented government; Government audit; Performance audit; The Balanced scorecard

\section{INTRODUCTION}

Government performance audit is refers to the independent audit institutions and auditors, in accordance with the laws and regulations of the state and people cognition of common standards, auditing and compliance audit in the traditional financial revenue and expenditure, on the basis of the government and the public sector as the performing functions and control public resources by using the "3E" (economy, efficiency and effectiveness) for review, analysis and evaluation, find and reflect the existing problems, and accordingly puts forward Suggestions for improvement, its purpose is to prompt the government and the public sector to strengthen the public responsibility, promote the government reasonable configuration and effective use of resources, economy, saving, efficiency, and obtain the best economic benefits and social benefits, while increasing the government macro management and decision level and ability, we'll establish a clean and efficient service-oriented government. Thus, to carry out government performance audit, not a new stage of development, but the government audit is to deepen the government administrative system reform, the transformation government function, the important measures to improve the government performance management.

In March 2005 for the first time the government work report in the form of official documents is put forward: "efforts to build a service-oriented government, innovation of government management mode, the combination of management and service, better for the grassroots, enterprise and society public service." These marks to establish "serviceoriented government" will be the goal of the administrative system reform of our country. With the development of China's economic and social challenges and opportunities in the transformation of our government is facing: to the public as the center, from the economy to a service-oriented transformation. Xi Jinping general secretary in January 2016 in Fujian's important speech, to speed up the transformation government function, we will reduce the decentralization, the pipes, optimization services, deepening the construction of institution efficiency, promote innovation, accurate service, parallel services. Visible, in order to provide higher quality of public services to the society, so as to adapt to the actual needs of the changing public pay more and more attention to construction of service-oriented government in our country. Government performance audit can improve the transparency of government financial funds use, for the social public to provide an access to government for the effective ways to use public funds, thus greatly promote the realization of the goal of building a service-oriented government in our country. At the same time, the service government's core function is to provide public services and public goods to the public, and to provide public service performance is the core content of government performance audit, therefore, under the background of the construction of the service-type government, the construction of government performance audit evaluation index system is especially important. Our country government performance audit also needs to meet the needs of the new public management development, building a service-oriented government performance audit mode [8]. But in the promotion and development face many problems; one of the biggest difficulties is that performance audit to lack of a measure of the public sector and the government evaluation criteria, and how to build a service-oriented government performance audit evaluation standard is a new difficult problem.

\footnotetext{
* Corresponding author
} 


\section{LITERATURE REVIEW}

The report, the party's 18 to build socialism with Chinese characteristics in accordance with the administrative system, further promote the separate government functions from enterprise management, we should separation of society and politics, the construction of functional science, structural optimization, honesty and high efficiency, people's satisfaction of a service-oriented government. Existing performance audit document, mostly from the perspective of government's own performance management to discuss the construction of the system of public organization performance problems. Public organization performance evaluation criteria of selection is varied, and weights set are different, so far also not form a set of recognized and generally accepted standard of performance evaluation of application. But from a public organization performance evaluation literature, some common evaluation index is available, and can be summarized as: the quality and quantity of output, efficiency, fairness, effectiveness, and service value and customer satisfaction of funds. By analyzing the related literature, the research of building the service-oriented government performance audit review.

\section{A. The research of the government performance audit}

Government performance audit is the inevitable developing trend of government audit, to build a serviceoriented government has a leading role in our country; the domestic scholars also have a lot of research. For example: temperature beauty instrument, $\mathrm{Hu}$ Guian (2007), Guo Jian mei (2009), Zhang Yan, Yang Jun (2011), angel lee (2012), Deng Xiaofang (2013), based on service oriented government construction course study, put forward the necessity of a service-oriented government performance audit in our country [1]. Gao $\mathrm{Yu}$ (2014) around the security factors, systematic audit procedures, audit method, audit index design, audit quality control, audit results of treatment and six aspects based on service-oriented government responsibility system of government performance auditing mode. However, scholars have only theoretically puts forward the importance of a service-oriented government performance audit, perfect for how to go from the actual performance audit mode highlights leading features, scholars have not specific further research.

For many years, the auditing profession on the many side of performance audit in China has carried out a lot of research work, the different Angle, and achieved positive results, but research areas are mainly concentrated in the overview and introduction to the basic concept of government performance audit, background, audit method, the basic theory of meaning and so on [7]. At present, our country government performance audit both at the theoretical level and practice, is still in the exploratory stage, especially for the construction of performance audit evaluation index of research is limited.

The research of building a service-oriented government performance audit evaluation index system.

Existing government performance audit evaluation literature, mostly from the government itself performance management point of view to discuss the construction of the index system of government performance audit, the selection of evaluation index is also varied, and the weight set also each are not identical, did not form a recognized and generally accepted set of evaluation index system of performance audit. For example: Xiao Zhendong (2007), Liu Aidong,Zhao Jinlin (2010),this paper discusses the performance evaluation system of the audit of public investment projects. Beside the English (2010)discusses the audit of public welfare project performance evaluation model. At the same time, throughout the performance evaluation of research results, most of scholars is to study the method level, the lack of the serviceoriented government performance audit evaluation index system of building specific indicators. Qiu Siqin, for example, (2011) stressed in the study of performance audit of fiscal supporting agriculture budget performance audit should pay attention to efficiency, output and results, emphasis on applying the balanced scorecard in public management of customers, financial, business process, learning and growth four aspects, such as the index, to evaluate and measure of government performance. Lin Wenshan (2011), applying the concept of the balanced scorecard to the design of performance audit evaluation criteria. Ancarani (2009) also think that the traditional performance evaluation of government audit focuses on the assessment of the quality of services and funds use value (the value for money), etc., but the government's public service performance should not only include these, more need to evaluate customer value (the value for the customer), realize the economy to a service-oriented transformation.

Performance audit evaluation system in our country, therefore, constructing the literature, mostly from aspects such as economy, social benefits and environmental benefits, research project evaluation index system of build problems, less involved in service-oriented government performance audit evaluation index system of building. For performance audit evaluation system to build only stay in the shallow level, unable to meet the needs of the public service oriented government performance evaluation [2]. At the same time, throughout the performance evaluation of research results, most of scholars are to study the method level, the lack of the service-oriented government performance audit evaluation index system of building specific indicators [3]. Our country government performance appraisal the one-sided pursuit of GDP growth, and even see economic development indicators as the only index, breeds "tournament" GDP in our country this kind of one-sided view. Lead to many local government one-sided pursuit of the high speed development of economy, and the related indicators focus on relationship between other people is not enough, affected the improvement of people's living standards, make society appeared the development deformity.

The new public service theory to the government performance audit provides a new Angle of view, that is the public interests as the core to citizens, citizens' satisfaction oriented to provide public services, pay close attention to public service response, fairness and democracy; Pay attention to the quality of public service, the effect; At the same time, focus on providing public services efficiency and economy [6]. Therefore, the government departments shall seriously implement the scientific concept of development, on the basis 
of efforts to create a good administrative environment, build in "public service" as the center of the administrative culture, strengthen the public servant consciousness, service consciousness, sets up the people-based values, not only to change the leading cadre to GDP about hero administrative view, but also from a certain extent, contributed to performance audit to guide the government pay more attention to social and public interests, the public satisfaction, and public service function, public liability, etc.

\section{THE AdVANTAGE OF THE BALANCED SCORECARD}

The balanced scorecard in retain the main financial indicators at the same time, introduces the related factors of future financial performance indicators: citizens, internal business process, learning and growing, it reflects the financial and non-financial balance; The balance of short-term and long-term; The balance of internal and external interest groups, and thus has a unique significance [9].

\section{A. The balanced scorecard to guide the target diversification of public service}

The new public service theory emphasizes the government should from the strategic height of thinking, to have democracy. From the perspective of our country is to build a service-oriented government construction vision: to realize the equalization of public service, to carry out the scientific outlook on development, promote the harmonious development of society [10]. And BSC (balanced scorecard) can put this vision and strategic objectives in the core role of the government public management, put forward the diversified, quantification, to implement the strategy of a service-oriented government performance indicators. BSC is an excellent daily performance management tool, BSC will organize strategic objectives into key performance indicators (KPI) system can be descriptive, transverse index decomposition to financial, customer, internal business dimensions, learning and growing $d$ four key dimensions of vertical will index according to the organization, department, team and individual layers of decomposition, to ensure that the height of the organizations at all levels goals with organizational goals consistent. So the balanced scorecard strategic objectives into target diversification and the segmentation function for non-profit organizations have good guidance and business plan, the organization may through the balanced scorecard to carry out the strategic goal of feedback and learning, can not only the correctness of the test target, and make timely adjustment on deviation of target. Balanced scorecard for performance evaluation of the knowledge economy era framed basic dimensions of paradigm and ideas, and has not limited the index selection of specific weights and dimensions. Specific dimension, evaluation index and weight according to the organization's objectives, operating characteristics, stage of development, environment and other factors, to set flexible and choices, its high flexibility for application of transforming in the public service performance audit evaluation schedule enough operation space [4].

\section{B. The balance of the balanced scorecard and the value of the new public service for consistency}

In order to achieve the profit target of the enterprise, the enterprise to provide customer satisfaction of products and services, pay attention to the quality of products and services, timeliness, obtain the acceptance and satisfaction of customers, to maintain the old customers, continue to come into potential new customers, to long-term to maintain and increase market share and long-term financial benefits and strategic goals finally be realized. This with the core values of the new public service: in order to serve the interests of citizens, responsiveness to citizens and needs, the pursuit of public interest, attaches great importance to the citizenship, have the same effect. At the same time, the new public service theory attaches great importance to the people-based, the pursuit of humanities concern not just concerned about efficiency. The balanced scorecard requires organizations identify customers' needs in time, timely, convenient to provide customers with services and products at the same time, more awareness of the foundations on which its existence is, the organization and employees to learn and grow continuously. So pay attention to humanistic management, emphasis on staff training and investment, emphasis on staff development and sense of belonging, and employee satisfaction as one of the important dimensions of evaluation organization performance.

\section{CONStruction OF THE PERformance Audit EVAluation SYSTEM BASED ON BSC}

\section{A. The core content of BSC}

The financial dimension:The balanced scorecard retains traditional financial index evaluation system, because the financial index evaluation system can be objective, neutral and unbiased reaction enterprise asset position, operating results, cash flow, can measure whether satisfy the interests of shareholders and investors, to realize the maximization of shareholder value.

The client dimension: Customer dimension as the balanced scorecard performance management system is an important part of, in order to make enterprises in formulating marketing strategies and tactics in when considering the demand of customers, enterprises should clear target customers and the needs of different target customers [5]. Modern management thought, the discretion of the customer satisfaction is the key to a successful enterprise, enterprise wants to obtain the longterm operating performance, it must create products and services by customers.

The internal business process dimension:In the aspect of internal business processes, mainly according to the needs of target customers to choose the key internal processes. It is not just concerned with supervision and improve the process cost, quality and time, but from the customer and shareholder expectations, internal processes are derived from the performance requirements. Internal business processes is the main process, form the competitive power of enterprise is the key to create value. 
The learning and growth dimension: Enterprise development to adapt to the change of product competition in the market, meet the long-term needs of target customers, we have to constantly improve the learning ability and level, to create value for shareholders and customers. Enterprises to achieve the goal of financial aspects of the, improve customer satisfaction and enterprise's production and operation efficiency, thus make the enterprise sustainable growth, must first be well prepared in terms of learning and growing, otherwise it will make the enterprise in other respects the effect of the efforts to sell at a discount greatly.

\section{B. Based on the BSC performance audit evaluation dimensions}

Based on the BSC, according to the characteristics of a service-oriented government at the same time, set the dimension and the order of the government performance audit evaluation. First, on the basis of the new public service theory of the pursuit of public interest maximization principle, the citizens in the first dimension of the government performance audit evaluation. Second, is to provide meet the requirements of the civil public service link, is the service process. Service process to guarantee the high quality of public service, is to determine the driver output results, public service is an important link to ensure the quality of public service. In other words, the service process dimension is for evaluation of the effect of government. Third, is the dimension to learn and grow latitude. Efficient and effective public service depends on the level of the learning and growth dimension. Construction of the people's livelihood depends on the development of the internal staff quality, the innovation of government work, the improvement of the government system. Fourth, is the public service into dimensions. The reasons are as follows: 1, the public service of input determines the overall level of citizens' effective demand and satisfaction; 2, the implementation of other process needs to be in a public service investment budget constraint down; 3, efficient performance of entrusted economic responsibility without the pursuit of efficiency. Based on BSC performance audit evaluation dimensions of public service architecture as shown:

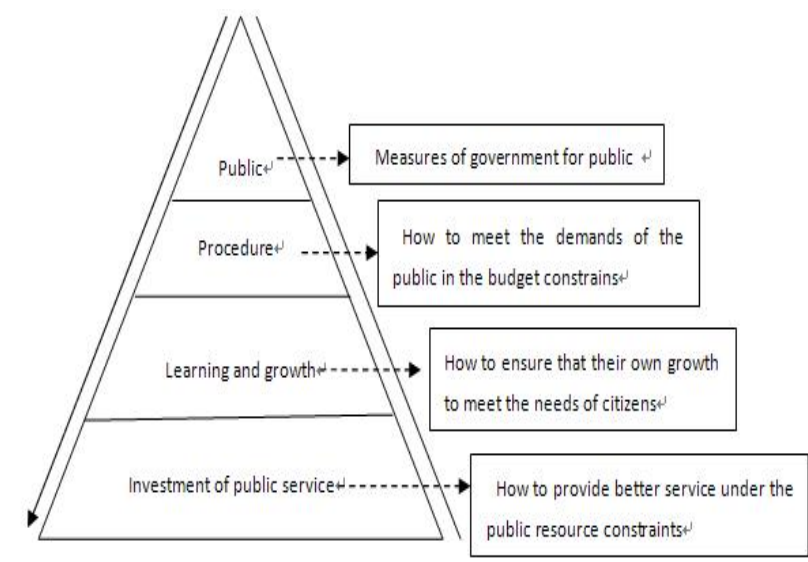

Fig. 1. Based on the BSC performance evaluation of public service dimension of architecture.

\section{Based on the BSC performance audit evaluation index set}

The public dimension: Government core tasks from the perspective of strategic development to identify the current environment of various public demand and the characteristics of demand, and provide services to meet the demand of the public. From the standpoint of the government performance evaluation of the public, therefore, the core of the results of evaluation indexes should be the public satisfaction, and public satisfaction depends on the government public service attribute index [11]. Public service properties index and can be divided into public service responsive (can identify needs and provide) and timeliness (efficiency), convenience of service, service quality, service attitude, service fairness and democracy (options, say, the quality of service feedback and processing) and related indicators.

The internal business process dimension: Internal business process dimension is to determine the government public service provided by a key link in the process of the properties of the output. Is the core of the government service ability and level reflected. In to ensure that the results of public administrative rationality at the same time, also must pay attention to the process of public administration rationality. Service-oriented government operation process generally includes: identification of service requirements, design or service process improvement, to provide services to the public, the follow-up service safeguard mechanism (quality feedback mechanisms and accountability mechanisms). So the specific evaluation should consider the following aspects: service demand social investigation mechanism, service demand forecasting mechanism; The scientific nature of the service process Settings (department of responsibilities clear, reasonable division of labor, coordination and execution smoothly and efficient service); Service process quality assurance measures, the standardization of the service process, service process compliance, humanized service process, service process transparency, interactive service process, service process of electronic level; Service feedback channels and accountability, as well as evaluation of emergency the emergency response mechanism.

The learning and growth dimension: Learning and growth dimension is to support the internal business processes and to provide public services, the public satisfaction, realize the basis of the harmonious development of society, so from a service-oriented government in the light of the demand of the reform should focus on the business training cadres and personnel of high quality; To strengthen the construction of information system and the transformation in support of the government affairs public, fair and effective demand; Adjust the organization structure, management system innovation, implementation of performance management, continue to deepen reform of the cadre and personnel system and democracy, openness, competition and merit, forming mechanism of cadre selection and appointment, scientific. So the evaluation indicators include: employee satisfaction, employee comprehensive improvement Suggestions for the improvement of service quality, employee number and adoption, information system and the degree of match process requirements, and the degree of the change of organizational 
culture, set the appropriateness and effectiveness of the management system of the various, etc.

The public service invest dimension: In particular, can be set up the annual budget, including human resources, material resources and information resources; Per capital investment; Capital, must be guaranteed to timely; The effective use of various resources, and goals and implementation situation such as budget control indicators. If from the state or local government of the whole public service into perspective, also will be involved in public service commitment structure rationality, the public service into the fairness of the index distribution.

\section{Based on the weight distribution of BSC performance audit evaluation}

Constructing evaluation index system of performance audit, is the key to the design and selection of indicators and to consider economic and social benefits, both universality and particularity, to basic covers all aspects related to the audit object benefits, and reasonably determine the weight of each index. Specific to auditing practice can be adopted in the method of subjective experience (Li bin (2011), Xu Hong, Qu Jing (2012)), analytic hierarchy process (Wang Xiaoli(2014), Wang Liyuan (2015)), questionnaire (Song Chang,Zhao Yiqing (2011), Wang Jianqiang (2015)), the weighting factor method (Zheng Guofang (2014)), and fuzzy comprehensive evaluation method (Fang Ning (2013), Zhang Jing (2013)), etc, and according to the feedback of the practice continuously adjust.

\section{CONCLUSION}

To sum up, the balanced scorecard principle for our government performance audit evaluation is pointed out that a scientific framework, flexible thinking, facing the different situation of the audited object, we can't determine the unified index system, there is no unified, weights of all owing to the different organizations, have no fixed pattern can be applied, even if the same organization will vary in different historical periods. Because of the excellence performance evaluation system is unique for every organization, must according to the needs and characteristics of each organization "tailored". This would require the auditors in practice constantly exploration, summary and revision, adhering to the service concept, and the evaluation and the auditees to fully communication, negotiation, obtains the support and cooperation of the auditees, can better and faster to promote the development of performance audit practice in our society.

\section{ACKNOWLEDGMENT}

I would like to express my gratitude to all those who have helped me during the writing of this thesis. I gratefully acknowledge the help of my supervisor Professor Gan Jiawu. I do appreciate him patience, encouragement, and professional instructions during my thesis writing. Last but not the least, my gratitude also extends to my family who have been assisting, supporting and caring for me all of my life.

\section{REFERENCES}

[1] Y. Zhang, J. Sun, "Based on the service-oriented government construction of government performance audit," Journal of accounting, 2011, pp. 61-63.

[2] J. Li, "Based on the service-oriented government of government performance audit research," Jiangxi university of finance and economics, 2012, pp. 25-32.

[3] X.F. Deng, "Service-oriented government performance audit research," central south university, 2013, pp. 30.

[4] Y. Gao, "Based on the service-oriented government perspective of government performance audit countermeasures study," Journal of internal audit in China, 2014, pp. 88-91.

[5] X.L. Wang and F.M. Wang, "Performance evaluation system for the audit institutions to build for the performance of the audit report," Journal of auditing research, 2015, pp. 52-59.

[6] M.Q. Wen, "Based on the perspective of government performance evaluation of government performance audit research," Journal of auditing research, 2007, pp. 27-30.

[7] M. Qu, "The government performance audit: evolution, framework and future," the northeast university of finance and economics, 2013, pp. 2535 .

[8] D. Han, "Service-oriented government orientation of government performance audit study - realistic significance, development obstacles and future development," Journal of internal audit in China, 2014, pp. 81-84.

[9] F. Zhou, "Based on the evaluation index system of government performance audit of the balanced scorecard to build research," Tianjin university of finance and economics, 2010, pp. 23-30.

[10] T.Q. Fu, "Based on the balanced scorecard to build government performance audit evaluation indexes," Journal of audit and economic studies, 2008, pp. 18-23.

[11] L.F. Zhu, "Application of the balanced scorecard in performance audit evaluation," Journal of internal audit in China, 2010, pp. 62-63. 